is entitled "A Dosage Schedule for Citrus Trees with Liquid Hydrocyanic Acid."

(Paper not presented for publication.)

Chairman H. J. Quayle: The next paper is entitled "The Stratification of Liquid Hydrocyanic Acid as Related to Orchard Fumigation." It has been prepared by Mr. R. S. Woglum and M. B. Rounds both of the Bureau of Entomology and will be presented by Mr. Rounds.

\title{
THE STRATIFICATION OF LIQUID HYDROCYANIC ACID AS RELATED TO ORCHARD FUMIGATION
}

By R. S. Woglum and M. B. Rounds, Bureau of Enlomology, Department of Agriculture, Alhambra, Cal.

The use in orchard fumigation in California of liquid hydrocyanic acid sometimes containing a large per cent of water has brought forth the question "Does this chemical ever stratify?" The prevalent opinion among those who have worked most with this active agent appears to be that stratification is improbable even when liquid hydrocyanic acid of widely different strengths or even liquid hydrocyanic acid and water are brought together in any proportion, and this view, at first, was accepted by the writers. The definite assertion to the senior writer by Mr. S. A. Stowell, an experienced fumigator, that he had drawn water and hydrocyanic acid from the same drum led to the outlining of a series of experiments in an endeavor to settle this point.

The first experiment which was performed by Mr. H. D. Young by slowly bringing together liquid hydrocyanic acid and tap water gave definite stratification. This preliminary experiment was followed by many others during which liquid hydrocyanic acid was added to tap and distilled water and vice versa; also liquid hydrocyanic acid of widely separated purities were brought together. In this work glass bottles were used each first being half-filled with material to which the second liquid was added slowly by means of a pipette. The bottles were not shaken. Typical experiments are herewith presented in brief.

In each of these eleven experiments stratification occurred regardless of the order in which the different liquids were added; the effect was similar whether the water was added to the hydrocyanic acid or the hydrocyanic acid to the water. Distilled water reacted in a manner similar to tap water. Each of these experiments was repeated and many others of like nature were performed. In every instance in 
Table 1. Table Representing the Results of Experiments on Stratification

\begin{tabular}{|c|c|c|c|c|c|}
\hline $\begin{array}{l}\text { Experiment } \\
\text { Number }\end{array}$ & $\begin{array}{l}\text { Size of } \\
\text { Bottle }\end{array}$ & $\begin{array}{c}\text { Liquid in Lower } \\
\text { Half of Bottle }\end{array}$ & $\begin{array}{l}\text { Liquid Added } \\
\text { to Half-Filled } \\
\text { Bottle }\end{array}$ & $\begin{array}{l}\text { Cloudiness of } \\
\text { Milky Appesrance }\end{array}$ & Stratification \\
\hline $\begin{array}{r}1 \\
2 \\
3 \\
4 \\
5 \\
6 \\
7 \\
8 \\
9 \\
10 \\
11\end{array}$ & 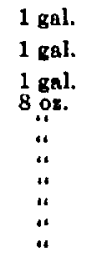 & $\begin{array}{l}\text { tap water } \\
\left\{\begin{array}{l}\text { tap water } \\
\text { tap } \\
50 \% \mathrm{HCN} 1 \\
150 \%\end{array}\right\} \\
\text { tap water } \\
\text { dis. water } \\
96 \% \mathrm{HCN} \\
\text { tap water } \\
\text { dis water } \\
50 \% \text { HCN1 } \\
92 \% \\
92 \% .\end{array}$ & $\begin{array}{l}92 \% \text { HCN } \\
\text { 192\%"“ } \\
192 \% " “ \\
96 \% " “ \\
96 \% \text { "“ } \\
\text { dis. water } \\
91 \% \text { HCN } \\
91 \% \text { "“ } \\
92 \% \text { " } \\
\text { dis. water } \\
\text { tap water }\end{array}$ & $\begin{array}{l}\text { Yes } \\
“ \\
“ " \\
“ \\
“ \\
\text { No } \\
\text { No } \\
\text { Yes } \\
\text { No } \\
\text { No }\end{array}$ & $\begin{array}{l}\text { Yes } \\
" 1 \\
" 1 \\
" 1 \\
" 1 \\
" 1 \\
" 1 \\
" 1\end{array}$ \\
\hline
\end{tabular}

1 Cloudiness in sample formed by diluting 96 per cent hydrocyanic acid to make a 50 per oent solution.

which the liquids were brought together slowly, stratification occurred. One series of bottles left undisturbed for several weeks showed distinct stratificiation throughout this period. If, however, the materials were brought together violently and thoroughly shaken stratification was not produced.

When liquid hydrocyanic acid was allowed to flow slowly into water near the surface level it rose to the surface and did not mix freely with the water. Ultimately a layer or stratum was formed between the heavier lower liquid and the lighter upper one. When water was added slowly to liquid hydrocyanic acid it flowed through the liquid to the bottom of the bottle forcing the lighter chemical to the top, and showed a distinct stratum between the two liquids. In some cases this stratum between the two liquids was transparent and detected only by close examination, or agitation of the bottle. In other cases a cloudiness or milky appearance was observed when water and hydrocyanic acid were mixed and this precipitate ultimately collected in the middle layer to which it gave a whitish gelatinous appearance. (Pl. 14, fig. 1.) When allowed to stand in bottles undisturbed for a short time a vigorous shaking was necessary to break up this layer.

This milkiness occured only with liquid hydrocyanic acid taken from galvanized iron drums. A chemical examination of the acid taken from drums showed it to contain traces of zinc in solution whereas the liquid hydrocyanic acid which produced no precipitate had been in glass containers and upon examination was found to contain no zinc. Since zinc was in solution in the liquid hydrocyanic acid and since zinc compounds with cyanogen are known to be insoluble in water, it would seem apparent that the precipitate formed was some compound of this metal. The presence of a gelatinous precipitate 
in the bottom of drums and in machines for applying the gas was often noted in field work during this past season, and was a source of interference with accurate action of the pump.

Actual proof of the fact that where liquids of widely varying purity are brought together stratification may take place and the relation thereto of zinc compounds present features of importance in field practice. In the first place only liquids of uniformly high purity should be used thereby to prevent stratification which might occur if materials of widely different strengths from two or more containers are poured together. Metals containing zine should not be brought in contact with liquid hydrocyanic acid. When drums are washed out with water after use in the field they should be thoroughly dried before being refilled. Furthermore, that stratification may hasten decomposition is shown by one experiment in which a gallon bottle half full of tap water was filled with 92 per cent hydrocyanic acid from a galvanized iron drum. A few days following the experiment decomposition started immediately below the middle layer which held the precipitate and within two weeks the lower half of the bottle was dark brown in color. The top layer remained perfectly clear until the completion of the experiment when the bottle was discarded to avoid explosion.

Chairman H. J. Quayle: These three papers are now open for discussion.

Prof. Geo. P. Gray: Our conclusions are the same regarding liquid $\mathrm{HCN}$ and its ability to stratify.

R. S. Woglum: There are a few rather interesting points which I wish to call your attention to in connection with our studies of liquid HCN.

Where the liquid is taken from iron drums the gelatine percipitate is hard to mix with the liquid HCN and stratification may be present when it is used.

There has been more daylight fumigation during the past summer with liquid HCN than ever before under the old system of fumigation. However I do not believe in daylight fumigation because the chances for burning are too great. In hot weather the gas from liquid $\mathrm{HCN}$ stays near the bottom of the tents and gives relatively better killings in the lower portions of the trees. At $40^{\circ} \mathrm{F}$. the killing is rather poor, although it may be said that in lower temperatures the best killings are at the top of the trees.

Champman H. J. Quayle: Our experiences show that there is less diffusion in low temperatures. At a temperature of $50^{\circ} \mathrm{F}$. there 

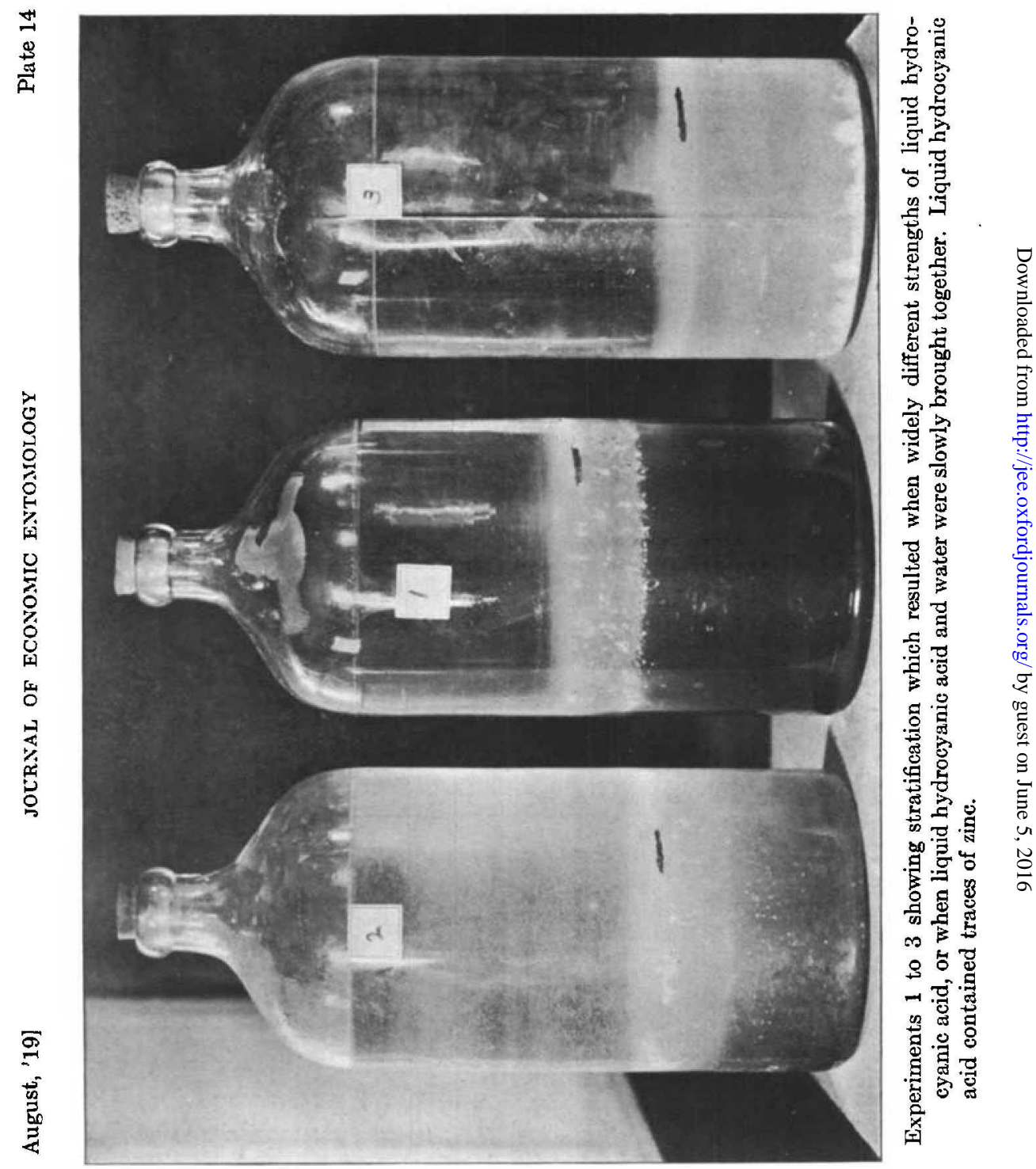
is a difference of 10 per cent between the top and bottom of the tent with the greater concentration and killing at the bottom. At a temperature of $70^{\circ} \mathrm{F}$. there is better diffusion and a more even killing throughout the whole tent.

If there is no further discussion we shall pass on to the next paper which was to have been presented by Dr. H. P. Severin of the University of California. As he could not be present I am going to ask $\mathrm{Mr}$. C. F. Stahl, of the Bureau of Entomology, U. S. Department of Agriculture, who is at present time located in Riverside studying the sugar beet leafhopper, and who has been doing considerable work on this insect for several years to read the paper which is entitled "Notes on the Behavior of the Beet Leafhopper."

Mr. C. F. STahl: Dr. Severin has prepared two very interesting papers on the beet leafhopper, both of which throw new light upon this insect. The title of the first paper has already been announced and the subject matter follows:

\section{NOTES ON THE BEHAVIOR OF THE BEET LEAFHOPPER (EUTETTIX TENELLA BAKER)}

By Henry H. P. Severix, Ph.D., California Agricultural Experiment Station

\section{Sexuar Behavior}

Dr. E. D. Ball ${ }^{1}$ noticed a swarming of the beet leafhopper (Eutettix tenella Baker) "near Pauguitch, Utah, at an elevation of 7,000 feet, just at the time the immense swarms swept over the beet regions of Utah in 1915. They were first observed in the evening just as the sun was setting and at this time were flying around and hovering over a little patch of young pigweed"; this was interpreted as an evening rest while migrating. "The next morning they were there in numbers, but quite sluggish with the cold. When this patch was visited a little later they were gone and none could be found in the valley." This observation was made in a mountain valley "above the limit of beet raising and no doubt above the limit of their breeding range," and was located in the approach to a mountain pass leading over to the southern desert.

In California the writer saw apparently the same behavior at 130 feet below sea level in the Imperial Valley and frequently in the beet fields and also on the plains of the San Joaquin Valley. The behavior is associated with mating and was first studied at Heber in the Imperial Valley on June $3-9,1918$, where an enormous congregation of nymphs and adults had occurred on the Nettle Leaf Goosefoot (Chenopodium

'Ball, E. D., 1917. Utah Agr. Exp. Sta., Bul, 155, pp. 28-29. 